\title{
Characterization of fracture liaison service non- responders after invitation by home visits and questionnaires
}

\author{
Citation for published version (APA):
}

van den Berg, P., van Haard, P. M. M., Geusens, P. P., van den Bergh, J. P., \& Schweitzer, D. H. (2020). Characterization of fracture liaison service non-responders after invitation by home visits and questionnaires. Osteoporosis International, 31(10), 2007-2015. https://doi.org/10.1007/s00198-02005442-9

Document status and date:

Published: 01/10/2020

DOI:

10.1007/s00198-020-05442-9

Document Version:

Publisher's PDF, also known as Version of record

\section{Document license:}

Taverne

Please check the document version of this publication:

- A submitted manuscript is the version of the article upon submission and before peer-review. There can be important differences between the submitted version and the official published version of record.

People interested in the research are advised to contact the author for the final version of the publication, or visit the DOI to the publisher's website.

- The final author version and the galley proof are versions of the publication after peer review.

- The final published version features the final layout of the paper including the volume, issue and page numbers.

Link to publication

\footnotetext{
General rights rights.

- You may freely distribute the URL identifying the publication in the public portal. please follow below link for the End User Agreement:

www.umlib.nl/taverne-license

Take down policy

If you believe that this document breaches copyright please contact us at:

repository@maastrichtuniversity.nl

providing details and we will investigate your claim.
}

Copyright and moral rights for the publications made accessible in the public portal are retained by the authors and/or other copyright owners and it is a condition of accessing publications that users recognise and abide by the legal requirements associated with these

- Users may download and print one copy of any publication from the public portal for the purpose of private study or research.

- You may not further distribute the material or use it for any profit-making activity or commercial gain

If the publication is distributed under the terms of Article $25 \mathrm{fa}$ of the Dutch Copyright Act, indicated by the "Taverne" license above, 


\title{
Characterization of fracture liaison service non-responders after invitation by home visits and questionnaires
}

\author{
P. van den Berg ${ }^{1}$ (D) P.M.M. van Haard ${ }^{2}$ - P.P. Geusens $s^{3,4}$ - J.P. van den Bergh ${ }^{3,4,5}$ - D.H. Schweitzer ${ }^{6}$
}

Received: 11 February 2020 / Accepted: 29 April 2020 / Published online: 13 May 2020

(C) International Osteoporosis Foundation and National Osteoporosis Foundation 2020

\begin{abstract}
Summary This study aimed to gain insight in specific characteristics and beliefs of FLS non-responders. Introduction The proportion of non-responding fracture liaison service (FLS) invitees is high but characteristics of FLS nonresponders are unknown.

Methods We contacted FLS non-responders by telephone to consent with home visit (HV) and to fill in a questionnaire or, if $\mathrm{HV}$ was refused, to receive a questionnaire by post $(\mathrm{Q})$, to gain insight in beliefs on fracture cause and subsequent fracture risk.

Results Out of 716 FLS invitees, 510 attended, nine declined, and 197 did not respond. Of these non-responders, 181 patients were consecutively traced and phoned until 50 consented with HV. Forty-two declined HV but consented with Q. Excluded were eight Qconsenters in whom no choice was offered (either $\mathrm{HV}$ or Q) and 81 patients who declined any proposition (non-HV|Q). $62 \% \mathrm{HV}$ and Q could recall the FLS invitation letter. The fracture cause was differently believed between HV and Q; the fall ( $96 \%$ versus $79 \%, p=.02$ ), bad physical condition ( $36 \%$ versus $2 \%, p=.0001$ ), dizziness or imbalance ( $24 \%$ versus $\mathrm{Q} 7 \%, p=.03$ ), osteoporosis ( $16 \%$ versus $2 \%$, $p=.02)$, and increased fracture risk ( $26 \%$ versus $17 \%, \mathrm{NS})$. Age $\geq 70$, woman, and major fracture were significantly associated with HV consent compared to Q (OR 2.7, 2.5, and 2.4, respectively) and HV compared to non-HV|Q (OR 16.8, 5.3, and 6.1).

Conclusion FLS non-responders consider fracture risk as low. Note, 50 patients (about 25\%) consented with a home visit after one telephone call, mainly older women with a major fracture. This non-responder subgroup with high subsequent fracture risk is therefore approachable for secondary fracture prevention.
\end{abstract}

Keywords FLS $\cdot$ Home visit $\cdot$ Non-respondence $\cdot$ Non-attendance $\cdot$ Osteoporosis $\cdot$ Questionnaire

\section{Introduction}

Osteoporosis care in patients with a recent fracture has been improved by the introduction of the Fracture Liaison Service

\section{P. van den Berg}

pberg@rdgg.nl

1 Department of Orthopedics and Trauma surgery, Fracture Liaison Service, Reinier de Graaf Hospital, Delft, The Netherlands

2 Department of Medical Laboratories, Association of Clinical Chemistry, Reinier the Graaf Hospital, Delft, The Netherlands

3 Department of Internal Medicine, Subdivision Rheumatology, Maastricht University Medical Center, Maastricht, The Netherlands

4 Hasselt University, Hasselt, Belgium

5 Department of Internal Medicine, VieCuri Medical Centre, Venlo, The Netherlands

6 Department of Internal Medicine and Endocrinology, Reinier the Graaf Hospital, Delft, The Netherlands model (FLS). This hospital initiative is firstly reported by McLellan et al. [1] and as such gradually regarded to be an optimal model of care [2-5]. Today, many FLS facilities experience the issue of low attendance rates being approximately $50 \%$ of all eligible patients $>50$ years [6]. Several factors are considered to contribute in FLS non-attendance, i.e., not interested, physically unable to attend such as patients after hip fracture, male gender, frailty, living alone, and also lower education [7, 8]. Lower education even accounted as independent risk factor and, therefore, points into the direction of anyone's capability of self-reflection and self-management and also into that of health illiteracy $[7,9,10]$. Apart from this, we discovered that flaws in the hospital registration led to 14\% less FLS attendance [7]. A strong cue for attendance is face-to-face contact between patient and health professional in order to convince patients to agree with a FLS visit [7]. Therefore, FLS policy must not only take care of potential errors in patient registration but also focus on patients' perspectives and opinions regarding fracture risk and subsequent fracture prevention [7, 11-13]. 
In the current study, we were particularly interested to broaden our insight into the characteristics and beliefs of FLS non-responders [14-16]. We aimed to contact FLS nonresponders by telephone to consent with HV during which they had to complete a questionnaire with the help of a FLS health professional if necessary or to consent to fill in a questionnaire which was sent by post (Q) in order to study the characteristics and motivations of these patients.

\section{Patients and methods}

\section{Study design and objectives}

This explorative study was conducted at the FLS of the Reinier de Graaf Hospital, Delft, The Netherlands. The intention of this FLS initiative is to encourage all patients $\geqq 50$ years to attend the FLS immediately following a fracture, in line with the Dutch Guideline on Osteoporosis and Falls [17]. After exclusion of patients who were deceased, all the following patients were not invited (according to the local FLS protocol): permanent nursing home residents, patients already on anti-osteoporosis treatment (not including calcium or vitamin D), or patients who had a DXA within 2 years before fracture. Two strategies were followed: (1) personal invitation by the health professional during fracture treatment as mandatory in the local FLS protocol and (2) sending invitation letters to all patients in whom the personal invitation was not made or to those who did not make an FLS appointment after receipt of the letter at 2 months after first admission at the emergency department.

This invitation strategy was performed by monthly screening of all fracture code registrations from the database of the emergency department to identify eligible patients. Data was extracted from the hospital entry registry (ChipSoft HiX 6.1) [18]. Then, retrieved data were used to prepare a mailing list to all eligible patients without a verifiable FLS appointment at 2 months after first attendance at the emergency department. Each letter consisted of the following items: an invitation to attend and an explanation about osteoporosis and information about appropriate care. For this study, recruitment lasted from $2017 / 8$ to $2018 / 4$. Non-responders were contacted by telephone by one experienced female FLS care health professional 8 weeks after the written invitation. During the phone call, patients were asked to consent with a HV to fill in a questionnaire about their drives and motives with regard to health issues. In case of no consent for $\mathrm{HV}$, patients were subsequently asked to consent to fill in the same questionnaire sent by mail (Q). In case of no consent for either HV or Q, patients were assigned to a third group (non-HV|Q). According to protocol, patients were phoned until a total of 50 patients had consented with HV. Eight patients were given no choice but $\mathrm{Q}$ as completion of HV was achieved. These patients were excluded from analysis. Note, during telephone calls, patients were not persuaded to accept our invitation to attend the FLS. This was on purpose in order to prevent people from feeling unsafe. Of all patients, available demographic data were used in the study (age, gender, fracture type, and death within 1 year after fracture) (see Fig. 1). After verification of the fracture location by $x$-ray, patients were categorized according to the classification of fracture locations proposed by Warriner et al. based on the probability that fractures were associated with osteoporosis: low risk for osteoporosis ranked as minor fractures and higher risk for osteoporosis ranked as major fractures, hip fractures, and vertebral fractures [19]. Categorized as minor fractures were clavicle/scapula, scaphoid, metacarpal, neck and head of radius, patella, ankle/malleolus, and metatarsal fractures. The definition for major fractures used in the models was a major, vertebral or hip fracture. In more detail, distal radius and lower arm, sub-capital humeral, rib, pelvis and acetabulum, tibia proximal/tibia plateau, and calcaneal/tarsal fractures as well as hip and vertebral fractures are classified as major fractures [19].

\section{Questionnaire}

The questionnaire for HV and Q patients highlighted three domains: Demographics, Tilburg Frailty Indicator (TFI) [20], and extrinsic/intrinsic motivations for the decision not to attend and personal arguments to abstain from attending, as formerly used in other studies [7, 11-16]. The TFI (a validated indicator of Frailty) ranges from 1 to 15 (Frailty $\geq 5$ ) [20]. Patients' own judgment of their personal health was analyzed binary according to a score of 1-6 as "poor" and 7-10 as "good." Extrinsic motivations were considered to arise from information by clinical professionals, for example, the inclination to follow a doctor's or plaster cast nurses' advice or to follow the instructions by the medical staff of the FLS. Intrinsic motivations were considered to be entered exclusively by self-reflection, i.e., anyone's personal beliefs to strive for a better bone health $[7,9,16]$.

\section{Aim}

The aim of the study was to make an inventory of characteristics and beliefs of 50 FLS non-responders who consented with $\mathrm{HV}$ and to analyze factors associated with consent for $\mathrm{HV}$ or Q.

\section{Statistical analysis}

Data were analyzed using Statgraphics Centurion software (Version 17.2.05 for MS-Windows; Statpoint Inc., Warrenton, VA, USA) and using R (2018, The R Foundation for Statistical Computing Platform, version 3.5.3). If numerical data could not be fitted with a Gaussian distribution 
Fig. 1 Flowchart of the study. Demographics used from patient charts were age, gender $\mathrm{M} / \mathrm{F}$, death, and fracture type. $* n=8$ were excluded for this study (received no request for HV).

Consecutive fracture patients $\geq 50$ years $\mathrm{N}=945$

(Deceased before FLS invitation $n=14$ )

Remaining $\mathrm{n}=931$

Exclusion for FLS invitation $n=215 / 931(24 \%)$

- Permanently institutionalized $\mathrm{n}=52(6 \%)$

- Being already on antiresorptive treatment $n=33(4 \%)$

- Recent DXA scan $n=22(2 \%)$

- Toe, finger and skull fractures $n=56(6 \%)$

- Living outside the hospital adherence region $n=52(6 \%)$

$\downarrow \rightarrow$\begin{tabular}{l|} 
Patients eligible for FLS invitation $\mathrm{n}=716 / 931(77 \%)$ \\
510 attenders $(71 \%)$ \\
9 responders but non-attenders, $(1 \%)$ \\
197 non responders $(28 \%)$
\end{tabular}

Untraceable non-responders $n=16(8 \%)$

Non-responders available for phone calls $n=181(92 \%)$

\section{$\downarrow$}

173 could be traced and included for this study*:

Consented with HV n= $50(29 \%)$

Consented with Q $\mathrm{n}=42(24 \%)$

No consent for HV or Q $\mathrm{n}=81(47 \%)$

Legends

Demographics used from patient charts were Age, Gender M/F, Death and Fracture type.

${ }^{*} \mathrm{n}=8$ were excluded for this study (received no request for HV)

[Shapiro \& Wilk \& Royston test or Micceri normality function (in R)], their mean of ranks or medians were compared using the Wilcoxon rank-sum test after checking for equal distributions using the Kolmogorov \& Smirnov test. Analyses were further performed on dichotomized age ( $<70$ or $\geq 70$ years), gender, and on all the (often binominal) variables of the questionnaire. In this study, age is a variable with multiple different integer values; we transformed it (according to the Dutch VMS) [21] so that the new variable has only two different values, $<70$ or $\geq 70$ years.

Associations were assessed by cross-tabulation, using as dependent variables HV and Q. After bivariate cross-tabulations, a multivariate logistic regression model was fitted to identify any possible association between the binary outcome variable $\mathrm{HV}$ and $\mathrm{Q}$ and various independent predictor variables, i.e., demographics such as age, gender, education, income, and physical conditions. Any association was assessed by direction and absolute value of adjusted Pearson residuals (resembling Z-scores). Evidence of any association in the population from which the sample was drawn was assessed with the unconditional, uncorrected Pearson's Chi-Square test, applying Monte Carlo sampling (10,000 resamplings) and if significant, measured using odds ratios and $95 \%$ confidence intervals. Multivariate odds ratios were estimated by logistic regression, with variable $\mathrm{HV}$ and $\mathrm{Q}$ as dependent outcome and Frailty (TFI dichotomized); age (numerical) and gender are included, and education, income, and physical conditions as independent variables after exclusion of those independent variables that were not significant in the univariate analysis and after testing for interaction between variables. Collinearity was analyzed using R's Condition Index applying a variance inflation factor (VIF) $>2.5$ and at least twice an Index $>0.5$ ). Where applicable, 95\% confidence intervals and correlation coefficients $>0.5$ were used. A $p$ value $<0.05$ was considered statistically significant.

\section{Ethics}

The study was carried out in accordance with the declaration of Helsinki and the guidelines of the International Conference on Harmonization Good Clinical Practice (GCP) after a certificate of no objection approved by the regional Medical Ethical Review Board (METC Zuidwest Holland) no. NL 17.108 .

\section{Results}

From 945 consecutive patients with a recent fracture, 229 were not invited at the FLS: 14 patients $(1 \%)$ deceased shortly after fracture; $52(6 \%)$ for permanent residence in nursery care; $33(4 \%)$ for priory-initiated anti-osteoporosis treatment; 
and $22(3 \%)$ because they had a DXA scan 24 months prior to this study; 56 (6\%) because of finger, toe, and skull fractures; and 52 patients $(6 \%)$ who were untraceable in our systems because of their residence outside the region of the hospital. Of the 716 invitees, 510 (72\%) attended the FLS, nine patients (1\%) responded but deliberately abstained from attending (FLS responders), and the remaining 197 patients (27\%) did not respond to the invitation.

The analysis of this study was focused on the 197 nonresponders. Of these patients, 181 could be traced and called and 16 patients could not be traced because of a no valid home address. None of these patients had a minor fracture, four had a major fracture, nine had a hip fracture, and three had vertebral fractures. During the inclusion period to complete assignment of 50 patients for $\mathrm{HV}$, another 42 patients declined $\mathrm{HV}$ but consented to fill in a questionnaire sent by post (Q) and 81 patients declined both HV and Q (the so-called non-HV|Q group). For the completion of this study, a total of 173 patients were called, see Fig.1. The remaining eight patients who were not given a choice other than to give permission for $\mathrm{Q}$ were excluded from the analysis because a $\mathrm{HV}$ was never offered to them. By April 2018, we finalized the recruitment of 50 patients for HV. Meanwhile, 42 agreed with Q and 81 had declined $\mathrm{HV}$ as well as Q (the non-HV|Q group).

\section{The recall of patient information in $\mathrm{HV}$ or $\mathrm{Q}$ patients}

None of the HV and Q patients could recall any face-to-face patient information in the hospital during the time of fracture treatment including advice to attend the FLS. Receipt of an FLS invitation letter was recalled by $68 \%$ of $\mathrm{HV}$ versus $55 \%$ of Q patients $(p=0.002)$.

\section{Factors associated with consent for HV or Q}

The proportion of patients that perceived a poor physical condition as the main cause of fracture was significantly higher in the HV compared to the Q group (36\% and 2\%, $p=0.0001$ ). The proportion of patients with a "poor" self-reported health was also significantly higher in HV than Q (50\% versus $24 \%$, $p=0.001$ ).

HV and Q patients considered falls, the accident, bad physical condition, and dizziness or imbalance as the main cause of recent fracture. In addition, the main cause of fracture was differently believed between HV and Q; the fall $96 \%$ versus $79 \%, p=0.02$; bad physical condition $36 \%$ versus $2 \%, p=$ 0.0001 ; and dizziness or imbalance $24 \%$ versus $7 \%, p=.03$, while for osteoporosis it was $16 \%$ in $\mathrm{HV}$ versus $2 \%$ in Q, $p=.02$ and the belief that subsequent fracture risk was increased; $26 \%$ versus $17 \%$, respectively (NS). There was no difference in patients' reports about having more than two chronic diseases or using more than four tablets per day, see Table 1.
According to univariate analysis, HV patients were older (age $\geq 70$ years; OR 17.3), with a higher contribution of women (OR 4.77) and more major fractures (OR 4.27). HV patients reported lower income more frequently (OR 6.78) as well as quality of life (OR 4.26) and weight loss after fracture (OR 3.09). Finally, more HV patients had walking difficulties (OR 3.97) and difficulties in maintaining balance (OR 6.83), more frequent hearing loss (OR 7.97), and loss of grip strength (OR 3.81). In both HV and Q, there was a moderate frailty prevalence and no significant difference between groups according to TFI (Frailty $\geq 5$ ). Only significant univariate associations to consent with HV versus Q are shown in Table 2.

In a multivariate model, three factors remained significantly associated with consent for HV versus Q: age $\geq 70$ years (OR 16.8), gender (women, OR 5.3), and major fractures (OR 6.1); the same three factors were associated with consent for $\mathrm{HV}$ versus non-HV|Q: (OR 2.7, 2.5, and 2.4, respectively). Age $<70$ years and minor fractures (OR 3.2 and 5.3, respectively) were associated to consent with $\mathrm{Q}$ versus non- $\mathrm{HV} \mid \mathrm{Q}$ (Table 3).

\section{Distribution of fractures among FLS non-responders and the patients who attended the FLS}

Distribution according to fracture type (major fractures including hip and vertebral fractures versus minor fractures) was compared between FLS attenders and traceable FLS nonresponders (Table 4).

The proportion of patients with major fractures in FLS attenders and traceable non-responders was similar 291/510 $(57 \%)$ and 109/173 (63\%). The proportion of major fractures was significantly higher in HV than in Q $(p<.0001)$ and non$\mathrm{HV} \mid \mathrm{Q}(p=.0001)$. In the latter two groups, minor and major fracture proportions were similar.

\section{Deceased patients}

Several patients with major fractures died within 12 months after initiation of the study; 3 patients in HV and 1 in Q), 6 patients in non-HV $\mid \mathrm{Q}, 5$ were deceased in not-reached patients and 5 were deceased in FLS attenders. In minor fractures, it was 1 patient in $\mathrm{HV}, 1$ patient in $\mathrm{Q}$, and 3 patients after minor fracture in the FLS attending group. All of the 16 untraceable individuals were elderly patients and 12 patients in this group had died within 12 months post-fracture.

\section{Discussion}

This study was specifically designed to characterize patients who did not respond to FLS invitation after a recent fracture and showed that it is feasible to trace and contact more than $90 \%$ of non-responders by one phone call of whom more than 
Table 1 Characteristics of FLS non-responders who consented with home visits or questionnaires

Home visit group $n=50(54 \%)$

Questionnaire group $n=42(46 \%)$

\section{Demographics}

Fracture type

Education

Yes

Age at Fracture: median (min, $\max$ )

All: no.: median (min, max)

Women: no.: median (min, $\max$ )

Men: no.: median (min, $\max )$

Minor fracture

Major fracture

Hip fracture

Vertebral fracture

Primary/secondary school versusHigh school/university

$3(6 \%)$

$29(69 \%)$

$13(31 \%)$

Country of birth

The Netherlands

Indonesia

Surinam

$49(98 \%)$

$39(93 \%)$

$1(2 \%)$

$2(5 \%)$

0

$1(2 \%)$

Income (in $€$ per month)

Low/normal $(€ 601-€ 1200) /(€ 1200 € € 1800)$

High $(\geq € 2100)$

$3(6 \%)$

$11(22 \%)$

No response

$26(52 \%)$

Living together (married/shared living)

Not married/divorced/widow/widower

$$
24(48 \%)
$$

$47(94 \%)$

$3(6 \%)$

Use of calcium, vitamin D supplementation and/or osteoporosis medication

Use of calcium tablets?

Yes

$8(16 \%)$

$6(14 \%)$

No

$42(84 \%)$

$24(48 \%)$

$26(52 \%)$

$7(14 \%)$

Yes

Use of vitamin D?

Yes

No

Do you already take antiresorptive medication?

Patient opinions

What caused your fracture:

Osteoporosis (yes/no; \%;

The fall (yes/no, \%)

The accident (yes/no, \%)

$p=0.02$

$p=0.01$

Bad physical condition (yes/no, \%)

NS

Imbalance/dizziness (yes/no, \%)

$p=0.0001$

$p=0.03$

In my opinion subsequent fracture risk is increased after fracture

Yes

$13(26 \%)$

No

$18(36 \%)$

$19(38 \%)$

$63(50,93)$

$n=42: 63(50,93)$

$n=22: 60(51,93)$

$n=20: 63(50,88)$

$23(55 \%)$

$17(40 \%)$

$2(5 \%)$

$23(55 \%)$

$13(31 \%)$

$6(14 \%)$

$23(55 \%)$

$19(45 \%)$

$42(100 \%)$

0

$36(86 \%)$

$15(36 \%)$

27 (64\%)

$2(5 \%)$

Do not know
$8(16 \%)$

$48(96 \%)$

$35(70 \%)$

$18(36 \%)$

$12(24 \%)$
$42(84 \%)$

$2(4 \%)$

$15(30 \%)$

$32(64 \%)$

$38(76 \%)$
$1(2 \%)$

$33(79 \%)$

28 (67\%)

$1(2 \%)$

$3(7 \%)$

$7(17 \%)$

$22(52 \%)$

$13(31 \%)$ 
Table 1 (continued)

\begin{tabular}{|c|c|c|}
\hline & $\begin{array}{l}\text { Home visit group } \\
n=50(54 \%)\end{array}$ & $\begin{array}{l}\text { Questionnaire group } \\
n=42(46 \%)\end{array}$ \\
\hline \multicolumn{3}{|l|}{ Perceived advice to attend the FLS } \\
\hline Perceived advice to attend the FLS by letter $=$ Yes & $34(68 \%)$ & $23(55 \%)$ \\
\hline Perceived advice to attend the FLS by letter $=$ No & $16(32 \%)$ & $19(45 \%)$ \\
\hline \multicolumn{3}{|l|}{ Taking interest in bone quality } \\
\hline Yes & $22(44 \%)$ & $14(33 \%)$ \\
\hline No/somewhat & $28(56 \%)$ & $28(67 \%)$ \\
\hline \multicolumn{3}{|l|}{ Various aspects of health and frailty } \\
\hline \multicolumn{3}{|l|}{ How healthy is your lifestyle? } \\
\hline Healthy & $31(62 \%)$ & $24(57 \%)$ \\
\hline Not healthy & $19(38 \%)$ & $18(43 \%)$ \\
\hline \multicolumn{3}{|l|}{ Self-reported level of health } \\
\hline Good & $25(50 \%)$ & $32(76 \%)$ \\
\hline Poor & $25(50 \%)$ & $10(24 \%)$ \\
\hline \multicolumn{3}{|l|}{ Do you suffer from 2 or more chronic diseases? } \\
\hline Yes & $17(34 \%)$ & $12(29 \%)$ \\
\hline No & $33(66 \%)$ & $30(71 \%)$ \\
\hline \multicolumn{3}{|l|}{ Do you take 4 or more tablets every day? } \\
\hline Yes & $25(50 \%)$ & $7(17 \%)$ \\
\hline No & $25(50 \%)$ & $35(83 \%)$ \\
\hline \multicolumn{3}{|l|}{ Frailty (Tilburg Frailty Indicator scores) } \\
\hline TFI score $\geq 5$ (frail) & $23(46 \%)$ & $13(31 \%)$ \\
\hline TFI score $<5$ (not frail) & $27(54 \%)$ & $29(69 \%)$ \\
\hline \multicolumn{3}{|l|}{ Parental hip fracture } \\
\hline Yes & $6(12 \%)$ & $6(14 \%)$ \\
\hline No & $44(88 \%)$ & $36(86 \%)$ \\
\hline
\end{tabular}

Results are presented as median (min, max) or no. (\%)

$25 \%$ agreed with a home visit, especially women of 70 years or older who sustained a major fracture. They primarily considered a fall, their bad physical condition, dizziness, or balance problems as the main cause of the recent fracture. Only one in five believed that subsequent fracture risk was increased, and a small proportion considered osteoporosis as
Table 2 Significant univariate associations to consent with home visit (HV) versus questionnaire (Q)

\begin{tabular}{llll}
\hline Factors & OR & $95 \%$ CI & $p$ value \\
\hline Age $\geq 70$ years & 17.3 & $6.03 ; 49.7$ & $<0.001$ \\
Woman & 4.77 & $1.81 ; 12.6$ & 0.001 \\
Low income & 6.78 & $1.74 ; 26.4$ & 0.003 \\
Self-rated low quality of life after fracture & 4.26 & $1.59 ; 11.4$ & 0.003 \\
Loss of weight after fracture & 3.09 & $1.09 ; 8.78$ & 0.03 \\
Difficulty in walking & 3.97 & $1.58 ; 9.99$ & 0.003 \\
Difficulty maintaining your balance & 6.83 & $2.31 ; 20.2$ & $<0.001$ \\
Poor hearing & 7.97 & $2.16 ; 29.4$ & $<0.001$ \\
Lack of strength in your hands & 3.81 & $1.27 ; 11.5$ & 0.013 \\
Age $\geq 70$ years and no frailty (TFI $\geq 5$ ) & 19.2 & $3.6 ; 102.0$ & $<0.001$ \\
Major fractures (no hip or vertebral fractures) & 2.89 & $1.2 ; 6.94$ & 0.02 \\
All major fractures (all major including hip and vertebral fractures) & 4.27 & $1.88 ; 51.59$ & 0.04 \\
\hline
\end{tabular}

OR: odds ratio; $95 \% \mathrm{CI}$ : 95\% confidence interval for population odds ratio; $p$ value $<.05$ is considered significant 
Table 3 Significant multivariate associations to consent with HV versus $Q$

\begin{tabular}{lll}
\hline Factors HV $(n=50)$ versus Q $(n=42)$ & OR $(95 \%$ CI $)$ & $p$ value \\
\hline Age $\geq 70$ & $16.8(5.0 ; 56.7)$ & $<0.001$ \\
Women & $5.3(1.5 ; 19.2)$ & 0.008 \\
Major fractures & $6.1(1.7 ; 22.3)$ & 0.0045
\end{tabular}

Multivariate associations in age (dichotomized at $\geq 70$ or $<70$ ), gender, and fracture type. Factors were first analyzed of association with each pair of groups using cross-tabulation, using adjusted standardized residuals and Chi-square/Fisher exact tests $p$ value for significance and odds ratio for measure of strength. OR: logistic regression odds ratio; 95\% CI: 95\% confidence interval for population odds ratio; $p$ value $<0.05$ is considered significant

underlying risk factor for subsequent fractures. As far as we know, the characteristics of FLS non-responders have not been studied before by home visits and questionnaires. Therefore, the current study design differs entirely from an earlier study by our group comparing personal opinions, drives, and motives of patients who were willing to share details of their decision to attend or not attend the FLS [7].

In this study, 931 fracture patients were identified of whom 716 were eligible for FLS invitation. According to daily FLS protocol, all of them should have received face-to-face invitation to attend the FLS (at any time during fracture treatment). Besides, patients who did not reply within 2 months had received a FLS invitation letter. Remarkably, most FLS non- attenders were non-responders to invitation $(n=197)$ and there were only nine responders who informed us that they refrained from FLS attendance after receiving the FLS invitation letter.

None of the HV or Q assigned patients could remember information face-to-face given by the health professional during fracture treatment meant to remind fracture patients about the urgency to attend the FLS (personal patient information is mandatory according to the local FLS protocol). It is conceivable that this information was not or insufficiently given since all patients of both groups were unanimous on the idea of lack of any given face-to-face patient information, while receipt of the FLS invitation letter was recalled by $68 \%$ of $\mathrm{HV}$ and $55 \%$ of Q patients. In addition, our FLS invitation letter was not designed to ask patients to inform our department if they were not willing or able to attend our FLS. It is emphasized that health illiteracy and the consequent incapability to properly understand the content of written information, albeit not tested in the current study, have been reported up to $40 \%$ in the elderly population $[9,10]$. These findings point at the importance of adequate FLS invitation strategies.

There are several studies reporting on clinical characteristics of FLS attenders but published data on FLS non-responders are limited. A telephone questionnaire study from Australia compared the 2-year outcome of FLS attenders with FLS nonattenders showing that FLS attenders had fewer new fractures and were more likely to be on treatment for bone fragility [22]. A similarly designed Dutch study showed also significant lower

Table 4 Distribution of age, gender, and fractures in FLS non-responders and attenders

\begin{tabular}{|c|c|c|c|c|c|}
\hline \multirow[t]{2}{*}{ Demographics/fractures } & \multicolumn{4}{|c|}{ FLS non-responders/non-attenders } & \multirow{2}{*}{$\begin{array}{l}\text { FLS attenders } \\
\text { FLS attenders } n=510\end{array}$} \\
\hline & $\mathrm{HV} n=50$ & $\mathrm{Q} n=42$ & Non-HV|Q $n=81$ & Not reached $n=16$ & \\
\hline Age at fracture (min, max) & $81(58,101)$ & $63(50,93)$ & $70(50,92)$ & $78(67,91)$ & $67(50,95)$ \\
\hline Women no. $(\%)$ & $n=42(84 \%)$ & $n=22(58 \%)$ & $n=53(65 \%)$ & $n=9(56 \%)$ & $n=363(71 \%)$ \\
\hline Median (min, max) & $81(58,101)$ & $62(51,93)$ & $67(50,92)$ & $79(72,84)$ & $67(50,95)$ \\
\hline Men no. $(\%)$ & $n=8(16 \%)$ & $n=20(42 \%)$ & $n=28(35 \%)$ & $n=7(44 \%)$ & $n=147(29 \%)$ \\
\hline Median (min, max) & $83(65,89)$ & $64(50,88)$ & $69(50,92)$ & $77(67,91)$ & $63(50,83)$ \\
\hline Minor fracture no. (\%) & $6(12 \%)$ & $22(52 \%)$ & $36(44 \%)$ & - & $219(43 \%)$ \\
\hline Deceased no. & 1 & 1 & - & - & 3 \\
\hline All major fractures no. (\%) & $44(88 \%)$ & $20(48 \%)$ & $45(56 \%)$ & 16 & $291(57 \%)$ \\
\hline Deceased no. & 3 & 1 & 6 & 5 & 5 \\
\hline Major fracture & 29 & 17 & 12 & 4 & 225 \\
\hline Deceased no. & 3 & 1 & 2 & 2 & 2 \\
\hline Hip fracture & 9 & 3 & 26 & 9 & 38 \\
\hline Deceased no. & - & - & 4 & 3 & 2 \\
\hline Vertebral fracture & 6 & 0 & 7 & 3 & 28 \\
\hline Deceased no. & - & - & - & - & 1 \\
\hline
\end{tabular}

Results are presented as median (min, max) or no. Deceased: study participants who retrospectively had died within 1 year after study start and closure of the study in no. Fractures were categorized according to Warriner [19]

Abbreviations: $H V$ consented with home visit, $Q$ consented to fill in a questionnaire, non- $H V \mid Q$ no consent for $\mathrm{HV}$ or $\mathrm{Q}$ 
mortality and $56 \%$ lower subsequent fracture rate in FLS attenders [23]. Similar results were also found in a Norwegian literature review [24]. Besides these outcome differences between FLS attenders and non-attenders, some studies evaluated the reasons for differences in FLS attendance among different centers. The first report on this issue albeit in a limited number of centers showed that attendance varied widely, between 20 and $89 \%$, together with a high variability in patient selection for FLS invitation [25]. In a study performed in The Netherlands, high compliance with the Capture the Fracture Framework Standards was shown in 24 analyzable FLSs. This study showed in particular that FLS attendance occurred in approximately half of all fracture patients [6].

Obtaining consent was time-consuming and approximately half of the patients declined to consent for participation. Remarkably, most HV consenters hardly needed any persuasion, while it took 8 weeks until all questionnaires were returned by $\mathrm{Q}$ patients. This difference may be explained by stronger concerns about health issues and fracture risk in the HV group compared to Q. Another study of the FLS found that older patients reported less mobility and more dependency on their caregivers for transportation to the hospital [8]. We speculate therefore that older patients consider a home visit as a solution for their inability to attend the FLS.

There were also similarities between both groups (HV and Q) noteworthy to report, i.e., a similar low-frailty prevalence (according to the TFI, frailty $\geq 5$ ) and a similar believed major reasons of fracture, i.e., the fall and accident. Another similar characteristic (39\% and $31 \%$, respectively) was the low proportion of knowledge of patients concerning increased subsequent fracture risk in agreement with previous reports [7, 9, $15,16]$.

ASBMR, IOF, EULAR, and EUGMS fully endorse the importance of secondary fracture prevention and FLS care is considered the most optimal approach in this respect [2-5]. To optimize FLS care according to this vision, the issue of attendance needs full attention.

This study has several weaknesses. (1) the study is an explorative study and therefore not based on preliminary determined statistical power. The outcome does not allow generalization outside this region and to other countries. (2) Age was dichotomously analyzed ( $<$ or $\geq 70$ years), threshold proposed by the Dutch VMS authority (Safety Management System) and commonly used for patient safety issues in hospital care [21]. Dichotomizing data can lower power in study outcomes. (3) We have no information on the exact number of patients who did or did not receive face-to-face patient information during fracture treatment encouraging them to attend the FLS.

In conclusion, a high proportion of FLS non-responders who participated in $\mathrm{HV}$ or Q consider subsequent fracture risk to be low. Nevertheless, 50 patients (about $25 \%$ of FLS nonresponders) consented with a home visit after one telephone call, mainly elderly women with a major fracture. These patients have a high subsequent fracture risk and are approachable for evaluation. The encountered approachability of FLS non-responders indicates that innovative strategies in optimizing FLS invitation can improve secondary fracture prevention care.

Acknowledgments We are grateful to Mrs. Sabine 't Hart, Mrs. Wil Aarssen, and Mrs. Maria van Woerden for their excellent secretarial services.

\section{Compliance with ethical standards}

Conflicts of interest None.

\section{References}

1. McLellan AR, Gallacher SJ, Fraser M, McQuillian C (2003 Dec) The fracture liaison service: success of a program for the evaluation and management of patients with osteoporotic fracture. Osteoporos Int 14(12):1028-1034

2. Akesson K, Marsh D, Mitchell PJ, McLellan AR, Stenmark J, Pierroz DD, Kyer C, Cooper C (2013) (IOF fracture working group). Capture the fracture $\AA$ : a best practice framework and global campaign to break the fragility fracture cycle. Osteoporos Int 24(8): 2135-2152. https://doi.org/10.1007/s00198-013-2348-z

3. Lems WF, Dreinhöfer KE, Bischoff-Ferrari H, Blauth M, Czerwinski E, da Silva J, Herrera A, Hoffmeyer P, Kvien T, Maalouf G, Marsh D, Puget J, Puhl W, Poor G, Rasch L, Roux C, Schüler S, Seriolo B, Tarantino U, van Geel T, Woolf A, Wyers C, Geusens P (2017 May) EULAR/EFORT recommendations for management of patients older than 50 years with a fragility fracture and prevention of subsequent fractures. Ann Rheum Dis 76(5): 802-810. https://doi.org/10.1136/annrheumdis-2016-210289

4. Eisman JA, Bogoch ER, Dell R, Harrington JT, McKinney RE Jr, McLellan A, Mitchell PJ, Silverman S, Singleton R, Siris E (2012 Oct) Making the first fracture the last fracture: ASBMR task force report on secondary fracture prevention. J Bone Miner Res 27(10): 2039-2046. https://doi.org/10.1002/jbmr.1698

5. Blain H, Masud T, Dargent-Molina P, Martin FC, Rosendahl E, van der Velde N, Bousquet J, Benetos A, Cooper C, Kanis JA, Reginster JY, Rizzoli R, Cortet B, Barbagallo M, Dreinhöfer KE, Vellas B, Maggi S, Strandberg T (2016) EUGMS Falls and Fracture Interest Group; European Society for Clinical and Economic Aspects of Osteoporosis and Osteoarthritis (ESCEO), Osteoporosis Research and Information Group (GRIO), and International osteoporosis Foundation (IOF). A comprehensive fracture prevention strategy in older adults: the European Union Geriatric Medicine Society (EUGMS) statement. J Nutr Health Aging 20(6):647-652. https:// doi.org/10.1007/s12603-016-0741-y

6. van den Berg P, Schweitzer DH, van Haard PM, van den Bergh JP, Geusens PP (2015 Sep) Meeting international standards of secondary fracture prevention: a survey on fracture liaison services in the Netherlands. Osteoporos Int 26(9):2257-2263. https://doi.org/10. 1007/s00198-015-3117-y

7. van den Berg P, van Haard PMM, Geusens PP, van den Bergh JP, Schweitzer DH (2019 May 25) Challenges and opportunities to improve fracture liaison service attendance: fracture registration and patient characteristics and motivations. Osteoporos Int 30: 1597-1606. https://doi.org/10.1007/s00198-019-05016-4 
8. Eekman DA, van Helden SH, Huisman AM, Verhaar HJ, Bultink IE, Geusens PP, Lips P, Lems WF (2014 Feb) Optimizing fracture prevention: the fracture liaison service, an observational study. Osteoporos Int 25(2):701-709. https://doi.org/10.1007/s00198013-2481-8

9. Raybould G, Babatunde O, Evans AL, Jordan JL, Paskins Z (2018 May 8) Expressed information needs of patients with osteoporosis and/or fragility fractures: a systematic review. Arch Osteoporos 13(1):55. https://doi.org/10.1007/s11657-018-0470-4

10. Heijmans M, Waverijn G, Rademakers J, van der Vaart R, Rijken M (2015) Functional, communicative and critical health literacy of chronic disease patients and their importance for self-management. Patient Educ Couns 98(1):41-48

11. Giangregorio L, Thabane L, Cranney A, Adili A, de Beer J, Dolovich L, Adachi JD, Papaioannou A (2010) Osteoporosis knowledge among individuals with recent fragility fracture. Orthop Nurs;29(2):99-107. doi: https://doi.org/10.1097/NOR. 0b013e3181d2436c. PMID: 20335769

12. Grover ML, Edwards FD, Chang YH, Cook CB, Behrens MC, Dueck AC (2014) Fracture risk perception study: patient selfperceptions of bone health often disagree with calculated fracture risk. Womens Health Issues;24(1):e69-75. doi: https://doi.org/10. 1016/j.whi.2013.11.007. PMID: 24439949

13. Alami S, Hervouet L, Poiraudeau S, Briot K, Roux C (2016) One barriers to effective postmenopausal osteoporosis treatment: a qualitative study of patients' and practitioners' views. PLoS One;11(6): e0158365. https://doi.org/10.1371/journal.pone.0158365

14. Ong T, Tan W, Marshall L, Sahota O (2015 Feb) The relationship between socioeconomic status and fracture in a fracture clinic setting: data from the Nottingham Fracture Liaison Service. Injury. 46(2):366-370. https://doi.org/10.1016/j.injury.2014.10.002

15. Boudreau DM, Yu O, Balasubramanian A, Wirtz H, Grauer A, Crittenden DB, Scholes D (2017 Aug) A survey of women's awareness of and reasons for lack of postfracture osteoporotic care. J Am Geriatr Soc 65(8):1829-1835. https://doi.org/10.1111/jgs.14921

16. Besser SJ, Anderson JE, Weinman J (2012) How do osteoporosis patients perceive their illness and treatment? Implications for clinical practice. Arch Osteoporos;7:115-24. https://doi.org/10.1007/ s11657-012-0089-9

17. Dutch Institute for Healthcare Improvement CBO (2011) Richtlijn osteoporose en fractuurpreventie. www.diliguide.nl/document/ 1015/file/pdf/. (Dutch) Assessed 14-02-2018
18. https://chipsoft.com $/$ ?Source=https $\% 3 \mathrm{~A} \% 2 \mathrm{~F} \% 2 \mathrm{Fwww} \%$ 2Echipsoft\%2En1\%2F. Assessed 14-02-2018

19. Warriner A ea. Minor, major, low-trauma, and high-trauma fractures: what are the subsequent fracture risks and how do they vary? Curr Osteoporos Rep 2011 Sep;9(3):122-128. doi: https://doi.org/ 10.1007/s11914-011-0064-1

20. Gobbens RJ, van Assen MA, Luijkx KG, Wijnen-Sponselee MT, Schols JMJ (2010 Jun) The Tilburg frailty indicator: psychometric properties. Am Med Dir Assoc 11(5):344-355. https://doi.org/10. 1016/j.jamda.2009.11.003

21. https://www.vmszorg.nl/wp-content/uploads/2017/11/web_2009. 0104 praktijkgids kwetsbare ouderen.pdf (Dutch) assessed 3012-2018

22. Van der Kallen J, Giles M, Cooper K, Gill K, Parker V, Tembo A, Major G, Ross L, Carter J (2014 Feb) A fracture prevention service reduces further fractures two years after incident minimal trauma fracture. Int J Rheum Dis 17(2):195-203. https://doi.org/10.1111/ 1756-185X.12101

23. Huntjens KM, van Geel TA, van den Bergh JP, van Helden S, Willems P, Winkens B, Eisman JA, Geusens PP, Brink PR (2014) Fracture liaison service: impact on subsequent nonvertebral fracture incidence and mortality. J Bone Joint Surg Am 96(4):e29. https:// doi.org/10.2106/JBJS.L.00223

24. Andreasen C, Solberg LB, Basso T, Borgen TT, Dahl C, Wisløff T, Hagen G, Apalset EM, Gjertsen JE, Figved W, Hübschle LM, Stutzer JM, Elvenes J, Joakimsen RM, Syversen U, Eriksen EF, Nordsletten L, Frihagen F, Omsland TK, Bjørnerem A (2018) Effect of a fracture liaison service on the rate of subsequent fracture among patients with a fragility fracture in the Norwegian Capture the Fracture Initiative (NoFRACT): a trial protocol. JAMA Netw Open 1(8):e185701. https://doi.org/10.1001/jamanetworkopen. 2018.5701

25. Vranken L, Wyers CE, van den Bergh JPW, Geusens PPMM (2017 Sep) The phenotype of patients with a recent fracture: a literature survey of the fracture liaison service. Calcif Tissue Int 101(3):248258. https://doi.org/10.1007/s00223-017-0284-1

Publisher's note Springer Nature remains neutral with regard to jurisdictional claims in published maps and institutional affiliations. 